\title{
DESIGN PARA A SUSTENTABILIDADE NA ECONOMIA DE MATERIAIS: USO DE RESÍDUOS NO DESENVOLVIMENTO DE PRODUTOS
}

\section{DESIGN FOR SUSTAINABILITY IN THE MATERIALS ECONOMY: USE OF WASTE IN PRODUCT DEVELOPMENT}

Debora Barauna, M.Sc. (UFPR);

Silvana Souza, Esp. (UTP); Fabiano André Trein, Dr. (UNISINOS);

Dalton Luiz Razera, Dr. (UFPR)

\section{Palavras Chave}

Economia Circular; Logística Reversa; Inovação Social; Economia Distribuída; Economia Criativa

\section{Key Words}

Circular Economy; Reverse Logistics; Social Innovation; Distributed Economy; Creative Economy

\section{RESUMO}

No universo da economia de materiais, do design e da sustentabilidade objetivou-se conhecer realidades brasileiras referentes ao uso de resíduos no desenvolvimento de produtos e suas relações com conceitos, normas e leis que propõem soluções para o panorama de escassez dos recursos naturais. Foram realizados pesquisa bibliográfica, pesquisa documental e estudo de caso de duas empresas que utilizam resíduos naturais (madeira, pedras e conchas) e industriais (poliuretano expandido) em seus processos e produtos. Os resultados obtidos evidenciaram o desconhecimento dessas empresas mediante aos conceitos emergentes estudados e a complexidade da legislação vigente quanto à valorização de resíduos como matéria-prima.

\section{ABSTRACT}

In the universe of the materials economy, design and sustainability, in this article was proposed to know the reality in Brazil about the use of waste in the product development and its relation with concepts, norms and laws that propose solutions to natural resources scarcity. It were carried out bibliographic research, documentary research and case study of two companies that use natural waste (wood, stones and shells) and industrial waste (expanded polyurethane) in the product development. The results evidenced the non-knowledge of the companies about the emerging concepts studied and the complexity of the current legislation that guides the valuation of waste as raw material in new production processes. 


\section{INTRODUÇÃO}

A natureza é caracterizada como o mundo material, onde vive o homem e existe independente das atividades humanas. É da natureza que os recursos naturais, bens de origem biológica, hídrica, energética ou mineral, são extraídos. O homem desde a sua existência utiliza os recursos naturais para a sua sobrevivência. No entanto, com o avanço do tempo, o desenvolvimento econômico e tecnológico transformou o consumo dos recursos naturais em recursos materiais, ou seja, em matérias-primas e insumos para a produção de excedentes, provocando o consumismo e o nascimento de uma Era Industrial. Porém, mediante às perspectivas de limites e esgotamento dos recursos naturais do planeta, princípios para a sustentabilidade ganharam força na sociedade e abalaram as estruturas da economia global. Uma tendência para o consumo consciente instaurou-se na sociedade. Na atualidade, o homem contemporâneo, cada vez mais, assume as consequências das suas ações e torna-se crítico quanto ao seu papel na sociedade e no meio ambiente. Assim, a compreensão da totalidade ou interdependência das coisas tem transportado a sociedade para uma nova Era, agora, Pós-Industrial.

Nesta transição para uma Era Pós-Industrial a sociedade contemporânea vive o surgimento de uma imersão de novos conceitos e mudanças que tem influenciado a economia ou gestão de materiais tanto de um país como de uma organização. Na passagem para o Século 21 novos cenários configuraram-se na sociedade remetendo à ideia de também uma Era do Design, relativo ao desenho de um novo mundo material. Em decorrência disto, conceitos foram criados a fim de elevar a gestão de materiais para patamares sustentáveis de interação com o meio ambiente, a sociedade e suas atividades. Dentre os conceitos, em foco neste estudo estão a noção de economia circular, logística reversa, inovação social, economia distribuída e economia criativa. Esses conceitos visam discutir o problema da demanda por novas formas de projetar o uso dos recursos materiais tornando-o mais significativo e aprofundando as relações com a ideia de um novo mundo material, no qual se tenha maior compreensão das consequências políticas, culturais, ambientais, socais e econômicas das escolhas de materiais e processos produtivos.

Assim, o objetivo do presente artigo foi estudar tais conceitos emergentes no universo da economia de materiais, do design e da sustentabilidade, considerando o uso efetivo destes por empresas que empregam resíduos no desenvolvimento de seus produtos. Para tanto, foi levantada bibliografia sobre o design para a sustentabilidade e a gestão de materiais, em específico da economia circular, da logística reversa, da inovação social, da economia distribuída e da economia criativa, além de políticas, normas e demais leis vigentes. Também, realizou-se estudo de caso de duas realidades brasileiras de uso de resíduos naturais (madeira, pedras e conchas) e industriais (poliuretano expandido - PU) no desenvolvimento de produtos. Os dados encontrados foram interpretados e sintetizados em uma breve revisão de literatura e na descrição dos casos estudados. As informações obtidas pelas sínteses realizadas foram relacionadas para discussão quanto à revalorização de resíduos como recursos materiais em processos produtivos. De modo geral, os resultados demonstram o desconhecimento das empresas diante dos conceitos emergentes abordados. No caso da realidade do uso de resíduos industriais, os procedimentos observados e exigidos por legislação mostraram-se complexos, o que evidencia o receio na utilização de resíduos desse contexto e dificulta a expansão do conceito da logística reversa. Já o uso de resíduos naturais mostrou-se mais flexível e inserido em conceitos como da inovação social e economia criativa. Por fim, em ambas as realidades foi observado vestígios do conceito de economia circular inseridos nos processos estudados, embora as empresas não conheçam tal conceito.

A seguir o artigo foi estruturado de modo a apresentar primeiro a síntese dos conceitos abordados, retratando a relação entre o universo da economia de materiais com o design e a sustentabilidade. $O$ detalhamento do método de pesquisa aplicado é exposto na sequência e depois os casos estudados são descritos e discutidos mediante à literatura.

\section{SUSTENTABILIDADE, DESIGNE ECONOMIA DE MATERIAIS}

A noção de interdependência das coisas tornou-se, Kazazian $(2005$, p.30):

[...] um precioso revelador de sentido de direção, quer se trate da biosfera ou de organizações humanas: qualquer fenômeno repercute no conjunto, que, por sua vez, mais ou menos tarde e de forma mais ou menos intensa, acaba repercutindo na fonte do fenômeno

Isto é evidente quando se trata das consequências da extração desordenada dos recursos naturais. Na sociedade contemporânea soluções para a manutenção das fontes naturais de fornecimento dos recursos materiais passaram a ser destaque em agendas mundiais de discussão sobre sustentabilidade e desenvolvimento humano. O fato é que durante muito tempo as consequências do crescimento econômico, com a expansão dos modos de 
produção e consumo, não foram consideradas sobre o meio ambiente. Só entre 1960 e 2010, em relação a todo o período anterior de existência da humanidade, a utilização dos recursos materiais foi aumentado 1.000 por cento (\%) (MCBRIDE (2011). Neste contexto, há perspectivas que a população mundial atual de 7,3 bilhões de pessoas (dados 2015) aumentará para 9,7 bilhões entre 2030 e 2050 (ONU, 2015). Caso essa estimativa se confirme, segundo o Programa das Nações Unidas para o Meio Ambiente em 2050 os mais de 9 bilhões de habitantes do planeta precisarão de 180 bilhões de toneladas anual de recursos materiais a fim de satisfazer as suas demandas. Quase três vezes mais que o valor de 70 bilhões de toneladas de matérias-primas extraídas em 2010 (UNEP, 2016). Toda atividade humana exerce impactos negativos sobre o meio ambiente. Entretanto, as ameaças que pesam sobre o mundo pesam também sobre cada indivíduo. Trata-se de uma relação que tem que ser construída ou reinventada entre o homem e a natureza. O desafio para uma reflexão global é produzir sem destruir e conceber um objeto do cotidiano tornando seu uso durável e seu fim assimilável por outros processos de vida (KAZAZIAN, 2005).

Dentro deste contexto, a vertente estratégica do design para a sustentabilidade, "coloca em ato descontinuidades locais promissoras, contribuindo para efetivas mudanças sistêmicas" (MANZINI, 2008, p.12). Isso faz referência também ao:

design e território; em outras palavras, desenhar e produzir: ao fazer escolhas e explorar recursos, dever-se-ia ter em mente o território em questão, além de como atender às necessidades reais dos habitantes (TAMBORRINI, 2012, p. 57).

A visão desse autor corrobora com critérios para a sustentabilidade defendidos por Manzini (2008, p.31) tais como, a consideração do "alto potencial regenerativo" das coisas e a importância de "aproximar pessoas e coisas" (MANZINI, 2008, p.33) antes de iniciar um processo de design. Para o autor é preciso desenvolver ecossistemas industriais que fechem o circuito de uso dos recursos materiais.

Entretanto, na economia ou gestão de materiais, da maioria das realidades industriais, as coisas descolam-se de modo linear entre a extração, a produção, a distribuição, o consumo e a destinação final dos resíduos. Este modo de gestão trata-se de um sistema em crise. O ideal é a economia dos materiais ser regida por um sistema em ciclo. É o que argumenta Annie Leonard, autora do documentário com mais de 50 milhões de visualizações no mundo. "A Histórias das Coisas" (THE STORY OF STUFF, 2016) bem como a Fundação Cradle to Cradle $^{\circledR}$ (C2C) com a teoria do 'berço ao berço'. A C2C propõe o conceito da economia circular e o processo de design para se pensar soluções para a gestão de materiais, considerando o desenvolvimento de toda a cadeia produtiva dos materiais e produtos por dois ciclos, um biológico e outro técnico (BRAUNGART e MCDONOUGH, 2013). A teoria do berço ao berço, "ao invés de tentar reduzir os fluxos de materiais lineares [...] prevê a sua reformulação em ciclos circulares de nutrientes" (EPEA, 2016, web). Assim, o valor uma vez criado, os resíduos gerados tornam para um novo ciclo natural (biológico) e/ou técnico (tecnológico) Bell (2011, p.6) explica que, muitos vezes "os produtos são desviados do fluxo de resíduos e convertidos em usos que apresentam maior valor quanto às suas aplicações originais" . Entretanto, McBride (2011) aponta para algumas questões que devem ser consideradas no desenvolvimento de produtos quanto à origem, ao fornecimento e ao uso dos recursos materiais: (i) Quais os possíveis impactos do seu uso para as comunidades locais e suas economias? (ii) Qual é a legislação dos agentes locais, onde os materiais são adquiridos? (iii) Como flui a econômica global e os seus impactos políticos? (iv) Qual a pegada de carbono de sua jornada de fornecimento até o usuário final? (v) Quais são os seus efeitos sobre a saúde dos envolvidos (engenheiros, designers, usuários, etc)? (vi) Quais os recursos adicionais e os efeitos da sua transformação para a produção? (vii) O que acontece com os produtos no fim do seu ciclo de vida?

Neste cenário, um conceito que se destaca é o da logística reversa. A Política Nacional de Resíduos Sólidos, Brasil (Lei n. 12.305, de 2 de agosto de 2010), em seu Art. $3^{\circ}$, inciso XII, descreve a logística reversa como um:

instrumento de desenvolvimento econômico e social caracterizado por um conjunto de ações, procedimentos e meios destinados a viabilizar a coleta e a restituição dos resíduos sólidos ao setor empresarial, para reaproveitamento, em seu ciclo ou em outros ciclos produtivos.

Na visão de Guarnieri (2016, p.11) a logística reversa é "o retorno de produtos consumidos e com pouco ou nenhum uso ao canal logístico, visando revalorizá-los". Na impossibilidade de revalorização, é necessário providenciar para o produto a destinação mais adequada em relação ao meio ambiente. O objetivo da logística reversa é a "obtenção de valores ambientais, logísticos, econômicos, legais e de competitividade pela diferenciação do nível de serviço logístico" (GUARNIERI, 2016, p.11).

Contudo, também é cada vez mais evidente a necessidade de mudanças no comportamento da sociedade, no que tange aos seus hábitos de consumo e colaboração na criação de soluções sociotécnicas ao meio ambiente. Assim, reforça-se a pertinência da ideia de inovação social. 
Na inovação social de acordo com Cipola (2012, p. 66) “os limites do modelo atual de produção e consumo" são reconhecidos em termos tanto ambientais como econômicos, sociais e institucionais. Neste conceito é considerado que "produtos, serviços ou modelos que atendem às necessidades sociais e criam novas relações e novos sistemas são socialmente inovadores" (TAMBORRINI, 2012, p.55). Uma inovação, por si só, é capaz de promover mudanças em padrões até então estabelecidos. Já no conceito de inovação social há "mudanças no modo como indivíduos ou comunidades agem para resolver seus problemas ou criar novas oportunidades" (MANZINI, 2008, p. 61). São soluções "guiadas mais por mudanças de comportamento do que por mudanças tecnológicas ou de mercado" (MANZINI, 2008, p. 61). Toda a inovação, seja ela impulsiona pela tecnologia, pelo mercado ou pela sociedade, apoia-se em três pilares para o seu desenvolvimento, a saber: (i) pessoas - ligado à existência de problemas complexos ou às demandas e necessidades das pessoas pela inovação; (ii) mercado - uma oportunidade de geração de negócio e (iii) tecnologia - o desenvolvimento de processos para transferir a inovação para a sociedade, sendo que uma inovação só ocorre quando fins econômicos e sociais são aplicados a essa. A diferença na inovação social é que o seu processo, geralmente, é gerido de modo horizontal ao invés de vertical de desenvolvimento e emergida de demandas "de baixo para cima" em vez daqueles "de cima para baixo" (MANZINI, 2008, p. 61). Trata-se de uma evolução quanto aos modelos de gestão, que, de igual modo, remete-se também ao conceito de economia distribuída.

Em uma estrutura economia centralizada o que prevalece é o controle total do sistema. Já na descentralizada cria-se novos nós de controle, mas ainda se mantém o sentido vertical do poder e com demandas que partem de cima para baixo. No caso de uma economia distribuída o poder vem da comunidade e das potencialidades locais (Figura 1).

Figura 01 - Evolução da estrutura econômica e social para redes distribuídas.

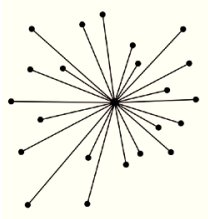

CENTRALIZADA

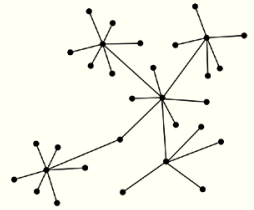

DESCENTRALIZADA

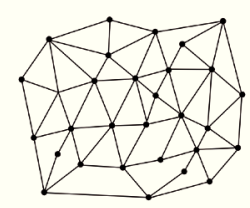

DISTRIBUÍDA
Fonte: Adaptado de Luoma, Vanhanen e Tommila (2011).

A economia distribuída é construída sobre conceitos modulares e multiplicáveis. Cada módulo, unidade ou local de produção é um nó de si próprio que está ligado a vários outros nós de acordo com as necessidades. O conceito da economia distribuída é baseado em uma economia de bioprodução, ou seja, na produção de bens e serviços por ecossistemas sustentáveis; uso de recursos biológicos renováveis; resíduos de um processo são matérias-primas para outro; e tecnologias operam em fluxos laterais. Também tratada como uma bioeconomia, essa visão requer o desenvolvimento simultâneo de modelos de produção e distribuição a nível local, evitando transportes de longas distâncias. Ao contrário da economia em escala, na economia distribuída os bens são produzidos localmente, com valor, em circuitos fechados e em redes. Diferentes tipos de indústrias de produção, utilização de resíduos e até mesmo a energia necessária para a produção são produzidos localmente. Assim, a economia distribuída refere-se tanto a um conceito de base biológica como a uma nova forma de pensar e viver de forma sustentável. Para Luoma, Vanhanen e Tommila (2011, p.11) "trata-se de uma questão transversal que afeta toda a sociedade". Ainda, de acordo com os autores, estima-se que em 2050 ecossistemas de negócios serão criados por centros e redes de valor mundiais. Novos conhecimentos e competências serão exigidos, aumentando cada vez mais a importância do capital humano. Enfim, a economia distribuída reforça a ideia já conhecida da abordagem do desenvolvimento sustentável: é preciso pensar globalmente e agir localmente.

Igualmente a inovação social e a economia distribuída outro conceito emergente na sociedade é a econômica criativa, onde há uma criatividade aflorada em novos sistemas, processos, produtos e serviços. A colaboração e as dinâmicas em redes também são enfatizadas. Usase a colaboração em redes ou a inteligência coletiva para a concepção de um novo mundo material, carregado de valores culturais, simbólicos, imateriais, além de ambientais, sociais, econômicos, políticos e territoriais (pertencimento). A economia criativa é um conceito emergente de uma nova sociedade, que envolve todo tipo de negócio ou indústria criativa e refere-se à diversidade cultural, inclusão social e sustentabilidade. "A busca pelo paradigma de produção econômica Pós-Industrial compõe o amplo cenário em que emerge o conceito de economia criativa" (MADEIRA, 2014, p.25). Todavia, a economia criativa resulta da tentativa de compreender a complexidade do mundo, onde a criatividade, a inovação e os riscos tornaram-se determinantes com o estabelecimento da competitividade (MADEIRA, 2014). Após surgir no Reino Unido em 1997, com a ideia de indústrias criativas ligadas a profissões específicas e a propriedade intelectual, 
a importância da economia criativa é reconhecido por quase todos os governos do mundo e amplia cada vez mais o seu escopo. (NEWBIGIN, 2016). No Brasil, em anos recentes, houve um avanço no comprometido com valores e demandas sociais. Uma política para a economia criativa chegou a ser pensada, com a inserção tanto de uma agenda política social como de metas econômicas específicas relacionadas com as exportações, a agregação de valor para os produtos brasileiros e o aumento da competitividade econômica (MADEIRA, 2014). No entanto, com a instabilidade econômica vigente no país, tal processo foi retardado. Por fim, considera-se "que o petróleo foi o principal combustível da economia do Século 20 e que a criatividade é o combustível do Século 21" (NEWBIGIN, 2016, p.6).

De modo geral, os variados conceitos apresentados surgiram, em parte, com a finalidade de adequar a economia de materiais de um país ou organização a um padrão ambiental e social mais eficiente diante de um mercado que se faz globalizado e de uma sociedade cada vez mais consciente das relações que se promovem com o meio ambiente. Cabe a esses países ou organizações saberem usufruir das ferramentas oferecidas por tais conceitos da melhor maneira, além de compreenderem quais funcionam melhor dentro de seus segmentos e quais não se encaixam. Por fim, relativo à sustentabilidade, ao design e à economia de materiais enfatiza-se que, de modo consistente, o design deve cooperar para a preservação das matérias-primas mundiais, equilibrando o seu fornecimento e uso pela economia de materiais. O desenvolvimento econômico da sociedade depende do fluxo de uso dos recursos materiais (McBRIDE, 2011). No entanto, evidencia-se a demanda por uma 'economia mais leve', expressão de Kazazian (2005), considerando que o meio ambiente e a economia não são questões antagônicas. Ao contrário disso, as questões ambientais relacionam-se muitas vezes com a saturação do mercado, com o controle regional dos recursos naturais e com a:

dificuldade de imaginar o futuro simplesmente como a continuação do passado, ou seja, como a reproposição de um modelo de desenvolvimento baseado em um crescente consumo material (MANZINI, 2008, p.20).

Na sequencia o conteúdo apresentado detalha o método de pesquisa empregado no artigo. É destacado o estudo de caso de duas empresas brasileiras de segmentos, totalmente, distintos que utilizam resíduos naturais e industriais no desenvolvimento de seus produtos.

\section{MÉTODO DE PESQUISA}

Este estudo foi desenvolvido no ano 2016 a partir da realização da disciplina "Inovação em materiais por meio do design", junto a um Programa de Pós-Graduação em Design no Brasil. No decorrer dessa disciplina foi proposto aos alunos o conhecimento de realidades referentes ao uso de resíduos no desenvolvimento de produtos, a fim de fomentar a discussão sobre conceitos relacionados a possíveis soluções de design para a sustentabilidade, tais como, a economia circular, a logística reversa e a economia distribuída, além da economia criativa e inovação social.

Especificamente, o estudo envolveu duas empresas localizadas na região norte de Santa Catarina, nacionalmente, considerada um polo industrial pela profusão de indústrias multinacionais, as quais geram resíduos em grande quantidade. As empresas em questão propiciaram a discussão de duas realidades diferentes do uso de resíduos no desenvolvimento de produtos no Brasil. Uma empresa representa a realidade do uso informal de resíduos para a criação de produtos artesanais com alto valor agregado, ora denominada de Empresa A. Tal empresa usa resíduos diversos do cotidiano com características naturais e renováveis no desenvolvimento de peças exclusivas, chamadas de biojoias por seus criadores. A outra empresa retrata um caso formal do uso de resíduos industriais como matéria-prima em processos de desenvolvimento de produto. Esta, por vez, determinada de Empresa B, desenvolve pranchas de bodyboard e segue toda a legislação vigente bem como procedimentos atribuídos pela empresa fornecedora dos resíduos. A escolha dessas empresas ocorreu pelo contato prévio dos pesquisadores com a apresentação do caso da Empresa A em um ambiente universitário da região e pela indicação da realidade da Empresa $B$ por um especialista em engenharia ambiental, também da região.

Enfim, o método empregado no estudo caracterizou-se pelo tipo de pesquisa 'estudo de caso' múltiplos, que consiste em "uma investigação empírica de um fenômeno contemporâneo dentro do contexto da vida real" (YIN, 2010, p.32). Assim, tratou-se de um estudo fenomenológico, de caráter qualitativo, descritivo e interpretativo dos fatos. As técnicas de pesquisa aplicadas para a coleta de dados foram pesquisa bibliográfica, documental e de campo. A pesquisa bibliográfica e documental considerou os conceitos como termos de busca e o filtro de publicações entre 2010 a 2016. A exceção foram autores de referências como Kazazian (2005) e Manzini (2008), além de normas e leis. Na pesquisa de campo os instrumentos 
utilizados foram máquina fotográfica para registro de imagens e questionário com questões abertas, conforme mostra a Figura 2.

Figura 02 - Questionário aplicado para os gestores das Empresas A e B.

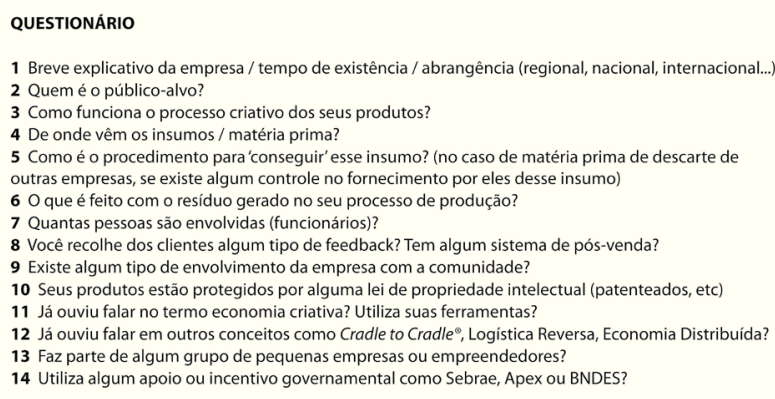

Fonte: Autores

O questionário foi formulado com a finalidade de aprofundar o conhecimento sobre a área de atuação e abrangência das empresas, seus processos e produtos, além de verificar como essas estão inseridas nos conceitos expostos pela pesquisa bibliográfica e documental. Este foi enviado via correio eletrônico para as empresas participantes e respondido pelo principal gestor da empresa.

A análise dos dados ocorreu: (i) por meio de interpretação da teoria encontrada no levantamento bibliográfico e documental; (ii) a partir da interpretação dos registros documentais e fotográficos da empresa; (iii) e por meio da transcrição das respostas relatadas no questionário pelas empresas. As informações geradas foram sintetizadas na revisão de literatura, previamente, descrita no artigo bem como pela descrição dos casos. Por fim, com o cruzamento das sínteses realizadas foram discutidos os resultados do estudo.

\section{RESULTADOS E DISCUSSÃO}

Os resultados apresentados na sequência referem-se às respostas obtidas pelo questionário e às fontes documentais fornecidas pelas empresas, tais como site oficial, relatórios e imagens. Esses descrevem a realidade das duas empresas estudadas em relação ao uso de resíduos como matéria-prima em seus processos e produtos.

A Empresa A segundo respostas do questionário aplicado surgiu com o objetivo de trabalhar com a criação de joias como "peças únicas, desenvolvidas artesanalmente com materiais em sua grande maioria naturais", representando a preocupação da empresa com a natureza. As peças são produzidas com fios de seda e de algodão, madeiras de descarte, pedras, conchas, corais entre outros. $\mathrm{O}$ público alvo da empresa são mulheres "independentes e que sabem valorizar a exclusividade de peças desenvolvidas com processos artesanais e de alto valor agregado". A ideia inicial de criação da empresa ocorreu em 2008 e em 2011 essa, oficialmente, foi fundada. A estratégia de venda dos seus produtos é por meio da internet, assim "não há barreiras regionais". O mercado principal da empresa é o nacional, mas já são atendidos clientes finais em vários outros países. Toda produção e administração da empresa é de origem familiar, realizada por três pessoas. Os produtos criados não são patenteados e protegidos por lei de alguma maneira, bem como a marca da empresa (Figura 3).

Figura 03 - Materiais e processo da Empresa A.

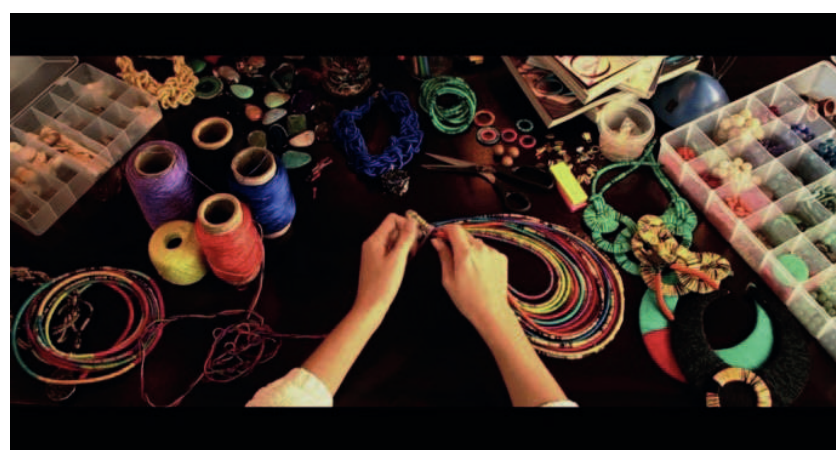

Fonte: Empresa A

A criação dos produtos da Empresa A é diária e não há limitações quanto ao processo criativo. Diante do critério de Manzini (2008, p.31) sobre a importância de "aproximar pessoas e coisas" antes de iniciar o processo de design, os criadores da Empresa A, a cada nova coleção, inspiram-se em diferentes lugares, povos e culturas, em tendências e em o que as mulheres que são sua referência estão usando. Também, buscam o uso de novos materiais e novas técnicas como inspiração. A maioria da matéria-prima utilizada pela empresa "é comprada de fornecedores de diversas partes do país, como Rio Grande do Sul Paraná, São Paulo, Minas Gerais, Amazonas etc.". As madeiras utilizadas são nobres, como a itaúba, pau marfim, cedro entre outras. Porém, respeitando a natureza, são madeiras colhidas em praias, trazidas pelo mar; sobras de construções ou mesmo reaproveitamento de móveis, todas esculpidas à mão. Neste caso, apesar de se observar a ideia de uma bioeconomia citada por Luoma, Vanhanen e Tommila (2011) na Empresa A, pela base biológica dos recursos materiais utilizados, não é possível considerar a empresa uma economia distribuída, pois a logística dos resíduos empregados poderia ser otimizada e o pertencimento local, a territorialidade, mais enfatizada. No 
entanto, globalmente a empresa destaca-se por realçar as riquezas naturais brasileiras em suas peças. No mais, "não existe exatamente um controle de fornecimento" dos resíduos para a empresa. O procedimento da aquisição é informal, a empresa entra em contato com as fontes e caso haja interesse na doação dos resíduos, esses são selecionadas de acordo com os critérios de produção da empresa. Segundo informações do site oficial da empresa a seda utilizada é feita, artesanalmente, a partir de casulos impróprios para a indústria, utilizando como base conceitual o naturalismo, a reciclagem e o compromisso social. Em sua maioria, a seda é tingida com corantes vegetais naturais, resultando em fios de seda pura de alta qualidade. No momento a empresa estuda uma solução para as sobras de fios, que estão armazenadas e não foram descartadas até então. De modo geral, sua produção gera pouco resíduo e a maioria é utilizada de alguma forma, como por exemplo, parte do pó da madeira é misturado com outros produtos e transformado-se em cola para ser utilizada nas peças. Este método de trabalho, além de ser um real exemplo da Era do Design, relaciona-se com a ideia de inovação social (MANZINI, 2008; CIPOLA, 2012; TAMBORRINI, 2012,) e economia criativa (MADEIRA, 2014; NEWBIGIN, 2016) por reforçar a união dos valores intangíveis dos materiais, a criatividade e o uso das redes digitais para ser global.

No entanto, em relação ao conhecimento da Empresa A quanto aos conceitos, previamente, citados e relacionados à economia de materiais, o único termo que foi reconhecido imediatamente, quando questionado, foi o da economia criativa. Outros conceitos como Cradle to Cradle $^{\circledast}$, logística reversa e economia distribuída não eram conhecidos. A Empresa A afirma encaixar-se nos parâmetros de uma economia criativa, sendo que uma das ferramentas mais utilizadas neste contexto é o processo colaborativo aplicado em diversas etapas da cadeia de valor da marca. Por exemplo, a empresa busca envolver a comunidade local em suas atividades, principalmente, no meio acadêmico, onde alunos de um curso de mestrado em design da região têm estudado novas possibilidades para os negócios da empresa. Também, as peças são comercializadas em grupos de pequenas marcas locais. Atualmente, a empresa participa do Moda Catarina do Serviço Brasileiro de Apoio às Micro e Pequenas Empresas (SEBRAE), onde está em andamento uma iniciativa, junto a algumas marcas de Santa Catarina, para a promoção de produtos e para o desenvolvimento local do Estado.

Já a Empresa B existe desde 2001 com a fabricação de artefatos de produtos químicos sintéticos com reciclagem de poliuretano expandido (PU). A empresa atua em todo o litoral brasileiro com a comercialização de pranchas do tipo bodyboard (Figura 4), que ocorrem por meio de lojas de produtos esportivos, supermercados e armarinhos. Sua administração e produção contam com 6 colaboradores ativos.

Figura 04 - Ambiente de trabalho da Empresa B.

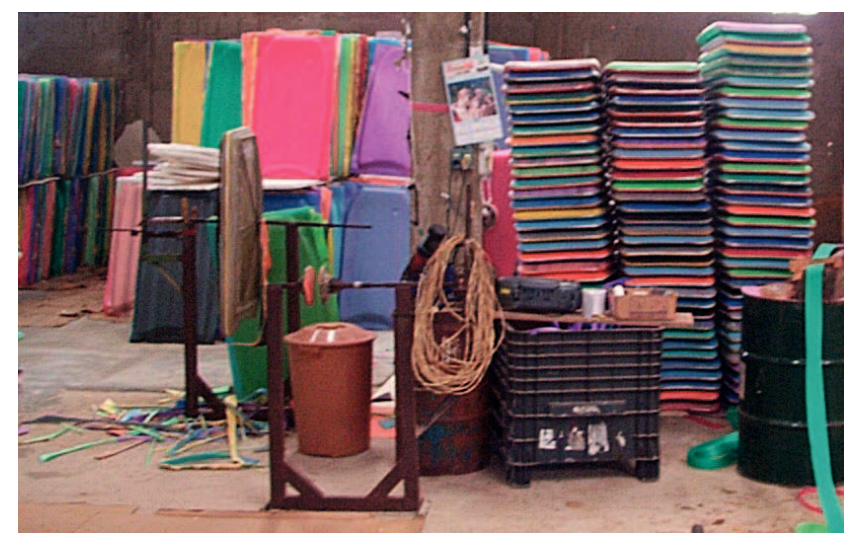

Fonte: Empresa B

As principais matérias-primas utilizadas pela empresa são chapas de EPS (isopor), polietileno (manta) e poliuretano expandido (PU). As chapas de isopor chegam pré-cortadas na empresa (no formato da prancha), necessitando às vezes de pequenos ajustes. Já o PU, produto obtido a partir da reação de dois componentes, o isocianato e o poliol, em estado líquido é incorporado ao processo como um resíduo industrial. Este é fornecido por uma indústria de grande porte da região, mediante concordância de seguimento dos procedimentos de controle exigidos. A indústria fornecedora do resíduo separa em tambores os descartes de isocianato e poliol líquido destinados à produção das pranchas, considerando o registro da quantidade destinada, procedência do destino e controle do novo uso. A Empresa $B$, recebedora dos resíduos, deve apresentar à indústria fornecedora os seguintes documentos:

a) Licença Ambiental de Operação (LAO/LO) fornecida pelo órgão ambiental estadual ou municipal.

b) Cadastro Anual de Atividades Poluidoras no Instituto Brasileiro do Meio Ambiente e dos Recursos Naturais Renováveis (IBAMA).

c) Alvará de funcionamento emitido pela prefeitura.

d) Inventário Nacional de Resíduos Sólidos Industriais, previsto na Resolução no. 313 (de 29/10/2002) do Conselho Nacional do Meio Ambiente (CONAMA).

Os resíduos gerados no processo produtivo das 
pranchas, desde que estejam sem contaminação de outros produtos, voltam para seus fabricantes, atendendo exigências das Política Nacional de Resíduos Sólidos (PNRS), Brasil (Lei n. 12.305, de 2 de agosto de 2010). No caso de resíduos contaminados, esses seguem para a destinação em aterro industrial, conforme a classificação do potencial poluidor desses resíduos descrita na ABNT / NBR 10.004/2004 e o conceito de logística reversa esclarecido por Guarnieri (2016). Tal procedimento também pode ser enquadrado na teoria Cradle to Cradle ${ }^{\circledR}$ de Braungart e McDonough (2013) pois resíduos tecnológicos voltam para um novo ciclo produtivo.

Quanto ao processo produtivo da empresa, esse é "totalmente artesanal", o que, apesar de a empresa desconhecer, neste caso se adéqua ao conceito de economia criativa descrito por Madeira (2014). Durante o processo produtivo são compreendidas as seguintes etapas:

a) Recebimento e armazenamento das matérias-primas - todas as matérias-primas recebidas são conferidas e posteriormente encaminhadas para o armazenamento. O armazenamento é realizado de acordo com o tipo de matéria-prima e é realizado no galpão da empresa.

b) Preparação/regulagem das máquinas e equipamentos e das matérias-primas - preparação e regulagem das máquinas e equipamentos a serem utilizados no processo produtivo bem como da seleção e preparação dos materiais a serem utilizados.

c) Processo produtivo - fabricação das pranchas propriamente ditas. O processo consiste basicamente na aplicação do PU (em estado líquido) sobre as placas de isopor (nas duas faces) para posterior acomodação/ sobreposição da manta de polietileno sobre as faces das placas de isopor. Em seguida, a prancha é colocada em formas especiais, para que ocorra a reação química de expansão do poliuretano e, consequentemente, a colagem da manta de polietileno na chapa de isopor.

d) Acabamento - consiste na retirada das rebarbas (manta de polietileno impregnada com poliuretano), aplicação do acabamento final (fita de polietileno para tampar, a junção das mantas, geralmente, coloridas) e aplicação do decalque (marca). O processo de aplicação da fita de polietileno é realizada através do aquecimento da mesma.

e) Controle de qualidade - para assegurar o atendimento das exigências feitas pelos clientes, a empresa realiza um rigoroso controle de qualidade nos serviços oferecidos. f) Depósito e expedição - após todas as etapas do processo produtivo, as peças são armazenadas no galpão da empresa e/ou despachadas diretamente para os clientes.

O feedback com os seus usuários ocorre somente por meio de pranchas que vêm a dar problemas. Também é inexistente o envolvimento da empresa com a comunidade local. Seu produto não é passível de patente, já a sua a marca tem registro no Instituto Nacional da Propriedade Industrial (INPI). A gestão da empresa não tem conhecimento sobre os conceitos questionados. No entanto, essa demonstrou interesse em conhecer, principalmente, o conceito e as ferramentas da economia criativa.

Sobretudo, ao relacionar os dados obtidos das duas realidades estudadas verificou-se que as empresas são de pequeno porte, com poucas pessoas envolvidas nos processos. Outro dado observado é que apesar da aquisição adversa dos insumos, uma por meios primários, outra seguindo a legislação vigente, o processo de produção permanece artesanal em ambos os casos. Também os casos destacam a afirmação de McBride (2011) sobre o crescimento econômico depender do fluxo de uso dos recursos materiais. Porém, ainda de acordo com o autor as fontes de fornecimento bem como o emprego desses pode ser otimizado. Em ambos os casos, de acordo com Bell (2011) os resíduos são desviados de um fluxo de rejeito e transformados em valor com a transformação de novos produtos. No entanto, somente a Empresa A usa tal valor como recurso de identidade corporativa. Já a Empresa B pode potencializar sua marca, diante dos aspectos ambientais empregados.

\section{CONCLUSÕES}

Concluí-se que princípios para a sustentabilidade foram realçados, junto ao desenvolvimento da sociedade $e$ mediante às perspectivas de limites e esgotamento dos recursos naturais do planeta. Por conseguinte, o design e a economia de materiais evoluíram e criaram conceitos a fim de contribuir para a mitigação do cenário apresentado. Esses conceitos (economia circular, logística reversa, economia distribuída, inovação social e economia criativa) são emergentes e buscam orientar empresas e países quanto ao desenvolvimento mais efetivo de suas atividades. Isto, diante de aspectos ambientais, sociais, econômicos, políticos, tecnológicos e culturais. A revalorização de resíduos nos processos produtivos e desenvolvimento de produtos são apenas uma das ferramentas instituídas.

Entretanto, por meio do conhecimento das duas realidades brasileiras estudadas observou-se que a maioria absoluta dos conceitos emergentes abordados eram 
desconhecidos pelas empresas em questão. Diante das políticas, normas e demais leis vigentes verificou-se, ain$\mathrm{da}$, a complexidade ao atendimento dessas por meio das empresas, sobretudo, daquelas de pequeno e médio porte. Com isso, foi destacado o uso informal dos resíduos naturais em um universo artesanal e criativo.

Enfim, os conceitos abordados mostraram-se complexos. Para estudos futuros sugere-se pesquisas específicas sobre cada conceito. É pretendido também o desenvolvimento de um framework com as bases conceituais citadas para demonstrar como essas se entrelaçam na relação proposta entre sustentabilidade, design e economia de materiais, especificamente, quanto ao uso de resíduos. Tal framework configurar-se-ia como um roteiro de procedimentos organizado em quatro grandes grupos que definem uma organização, tais como: empresa (seu contexto, estratégias e ferramentas que cabem ao todo da organização); recursos materiais (questões e diretrizes para se pensar e planejar a seleção das matérias-primas e insumos para uso nos produtos); processos (questões e diretrizes para se pensar e planejar os procedimentos que devem ser trabalhados quanto aos processos de produção dos produtos) e produtos (questões e diretrizes para se pensar e planejar as características que os produtos devem possuir diante da difusão desses na sociedade).

\section{AGRADECIMENTOS}

Nossos agradecimentos para a Coordenação de Aperfeiçoamento de Pessoal de Nível Superior (CAPES) pela bolsa de doutorado destinada à primeira autora do trabalho.

\section{REFERÊNCIAS}

ABNT, ASSOCIAÇÃO BRASILEIRA DE NORMAS TÉCNICAS, NBR 10004. Resíduos sólidos: classificação. Rio de Janeiro, 2004.

BELL, B.. Material Intelligence: An Overview of New Materials for Manufacturers. PF Innovation, Canadá, 2011.

BRAUNGART, M.; MCDONOUGH W. Cradle to Cradle: Criar e reciclar ilimitadamente. $1^{\mathrm{a}}$ ed., Editora G. Gili, São Paulo, 2013.

BRASIL. [Lei n. 12.305, de 2 de agosto de 2010]. Política nacional de resíduos sólidos [recurso eletrônico]. - 2. ed. - Brasília : Câmara dos Deputados, Edições Câmara, Série legislação, n. 81, 2012.
CIPOLA, C.. Design, inovação social esustentabilidade. In: Cadernos de Estudos Avançados em Design: inovação / organização: Dijon De Moraes, Itiro lida, Regina Álvares Dias - Barbacena: EdUEMG, p. 65-79, 2012.

CONAMA, CONSELHO NACIONAL DO MEIO AMBIENTE. Gestão de resíduos e produtos perigosos: dispõe sobre o inventário Nacional de Resíduos Sólidos Industriais. Resolução n 313, de 29/10/2002, Brasília, 2002.

EPEA. Cradle to Cradle. Disponível em: <ttp://epea-hamburg.org/en/content/cradle-cradle-certifiedtm-certification>. Acesso: jan. 2016.

GUARNIERI, P.. Logística Reversa: Desafios e Oportunidades no Brasil e no Mundo. Revista em Gestão, Inovação e Sustentabilidade - Brasília, v. 2, n. 1, p. 11-16, jun. 2016.

KAZAZIAN, T.. Haverá a idade das coisas leves: design e desenvolvimento sustentável. São Paulo: Editora Senac, 2005.

MADEIRA, M. G.. Economia criativa: Implicações e desafios para a política externa brasileira.Brasília: FUNAG, 2014.

MANZINI, E.. Design para a inovação social e sustentabilidade: Comunidades criativas, organizações colaborativas e novas redes projetuais. Cadernos do Grupo de Altos Estudos. Rio de Janeiro: E-papers, v.1, 2008.

MCBRIDE, M.. Catalyst: Strategic Design Review. n.7, 2011.

NEWBIGIN, J.. What is the creative economy? From 'creative industries' to 'creative economy' - how the idea of creative industries and the creative economy has changed in the last 20 years. Creative Economy, British Council UK, 2016. Disponível em: < http://creativeconomy.britishcouncil.org/guide/what-creative-economy/>. Acesso em: dez 2016.

ONU, United Nations, Department of Economic and Social Affairs, Population Division. World Urbanization Prospects: The 2014 Revision, (ST/ESA/SER.A/366), 2015.

LUOMA, P.; VANHANEM, J.; TOMMILA, P.. Distributed Bio-Based Economy: Driving Sustainable Growth. Sitra, 2011. 
UNEP, United Nations Environment Programme. Global material flows and resource productivity: Assessment Report for the UNEP International Resource Panel, 2016.

TAMBORRINI, P.. Design de inovação. Do design ao design de sistemas: objetos, relações e comportamento. In: Cadernos de Estudos Avançados em Design: inovação / organização: Dijon De Moraes, Itiro lida, Regina Álvares Dias - Barbacena: EdUEMG, p. 53-63, 2012.

THE STORY OF STUFF. Disponível em: <http://storyofstuff.org/about/>. Acesso em nov. 2016.

YIN, R. K. Estudo de Caso: Planejamento e Métodos. 4 ed. Porto Alegre: Bookman, 2010. 